Bangladesh J. Bot. 36(2): 121-125, 2007 (December)

\title{
GENETIC DIVERSITY IN POTATO (SOLANUM TUBEROSUM L.)
}

\author{
M.A.A. Mondal ${ }^{*}$, M.M. Hossain ${ }^{1}$ M.G. RASUl ${ }^{2}$ AND M. Shalim UdDin ${ }^{3}$ \\ Agricultural Research Station, Burirhat Farm, Rangpur, Bangladesh
}

Key words: Genetic diversity, Cluster analysis, Potato

\begin{abstract}
Genetic diversity in 31 potato genotypes (parents and their hybrid progenies) was determined using multivariate analysis. Cluster analysis revealed that the parents and their hybrid progenies could be grouped into five different clusters. The maximum number of genotypes were included in clusters II and V. Cluster V had maximum and cluster I had minimum intra-cluster distance. Cluster mean showed wide range of variation for several characters among single as well as multi-genotypic clusters. Considering diversity pattern, parents should be selected from clusters I, III and V for the improvement of potato.
\end{abstract}

\section{Introduction}

Potato is the fourth most economically important food crop after wheat, rice and maize in the world. The crop has high nutritional value as well as great yield potential. The existence of variability in a particular trait is an important prerequisite for its heritable improvement. For improving the yield potential of varieties and hybrids the decision should be made about the choice of right type of parents for hybridization. Since potato is a vegetatively propagated crop, variation among the existing commercial cultivated varieties seldom occur. Therefore, induction of variability in potato is urgently needed for ultimate use in any crop improvement programme.

It has been found that the progenies derived from crossing between divergent parents give divergent and useful trait. It has been often postulated by the breeders that geographical distribution reflects genetic diversity in selecting parents for hybridization. A limited study has been made on genetic divergence in potato either at tetraploid (Gaur et al. 1978, Sidhu et al. 1981 and Singh et al. 1988) or at diploid level (Grag 1988). An understanding of the nature and magnitude of variability among the genetic stocks is of prime importance to the breeders. Genetic diversity is one of the important tools to qualify genetic variability in both cross- and selfpollinated crops (Murty and Arunachalam 1966, Gaur et al. 1978). Such a study also permits to select the genetic divergent parent to obtain the desirable recombinant in the segregating generations. Therefore, the present study was undertaken to analyze the genetic divergence in 31 potato genotypes.

\section{Materials and Methods}

Thirty one genotypes of potato were grown in the research field of Institute of Biological Sciences, Rajshahi University, Rajshahi. The experimental design was RCBD with four replications. Each replication consists of 31 plots. Each plot having two rows of 40 plants. Row to row and tuber to tuber distance was 60 and $20 \mathrm{~cm}$, respectively. Recommended dose and application methods of fertilizers were used. To get good crop conditions irrigation, intercultural operations, spraying of insecticide and fungicides were performed. The planting was done on 15 November 2001 and the harvesting was made after 90 days of planting. Observations were recorded and calculated on ten randomly selected plants from each plot on days to emergence (DE), plant height (PH), number of stems/plant (NS), number of tubers/plant (NT), tuber weight/ plant (TW), individual tuber weight per plant (ITW), tuber dry-matter content (DM\%) and tuber

*Corresponding author. E-mail: pso.burri@bari.gov.bd, ${ }^{1}$ Department of Botany, Rajshahi University, Rajshahi-6205, Bangladesh. ${ }^{2}$ BSMRAU, Gazipur, Bangladesh. ${ }^{3}$ Plant Breeding Division, BARI, Gazipur, Bangladesh. 
weight loss due to respiration 150 days after harvest (TWL\%). Data were subjected to principal component and Mahalanobis (1936) $\mathrm{D}^{2}$ analysis extended by Rao (1952) using GENSTAT 513 Computer programme.

\section{Result and Discussion}

Analysis of variance revealed that the differences in 31 potato genotypes/varieties were significant for all the characters indicating the presence of notable genetic variability among them. The $\mathrm{D}^{2}$ values ranged from 3.823 to 23.694 and principal component scores also indicated a high degree of genetic diversity among the genotypes.

Cluster analysis: By application of non-hierarchical clustering using co-variance matrix, 31 genotypes (parents and their hybrids) of potato were grouped into five different clusters (Table 1). It was revealed that clusters II and IV had the maximum number of genotypes (nine) followed by cluster V and III having seven and five genotypes each, respectively. Cluster I had only one genotype and it was the lowest. Clustering pattern of parental genotypes under this study reveals that parents showed considerable genetic diversity among themselves by occupying four different clusters. Similar results were reported by Gaur et al. (1978) in potato, Masud et al. (1995) in pumpkin, Mannan et al. (1993) in Colocasia esculenta and Singh and Singh (1979) in okra. The 21 hybrids were distributed into four different clusters having more than one hybrid in each cluster. In some cases, the hybrid and one of its parents occupied the same cluster as in clusters II, IV and V. Similar results were reported by Main and Bahl (1989) and Singh and Prasad (1991). Intercluster hybrids were more frequent among hybrids with significant heterosis though the expression of heterosis was better in intercluster hybrids because of high mean performer of the parents and their different origin. Shanmugam and Rangasmy (1982) reported that falling materials of same origin into different clusters was an indication of broad genetic base of the genotypes belonging to that origin. Most of the female parents were grouped in cluster $\mathrm{V}$ indicating low genetic diversity among these parents. This could be due to their narrow genetic background.

Table 1. Distribution of 31 potato genotypes among five clusters.

\begin{tabular}{ccl}
$\begin{array}{c}\text { Group/cluster } \\
\text { No. }\end{array}$ & $\begin{array}{c}\text { No. of } \\
\text { genotypes }\end{array}$ & \multicolumn{1}{c}{ Genotypes in different cluster } \\
\hline I & 1 & $\begin{array}{l}\text { Dheera } \\
\text { II }\end{array}$ \\
& 9 & $\begin{array}{l}\text { Shill Bilati } \times \text { TPS-67, Shill Bilati } \times \text { Dheera, Lal Pakri } \times \text { Dheera, Sada } \\
\text { Gutti } \times \text { TPS-67, Ausha } \times \text { TPS-67, Patnai } \times \text { TPS-67, Patnai } \times \text { TPS-13, } \\
\text { TPS-67, TPS-13 }\end{array}$ \\
III & 5 & $\begin{array}{l}\text { Lal Shill } \times \text { TPS-67, Lal shill } \times \text { Dheera, Lal Pakri } \times \text { TPS-13, Ausha } \times \text { TPS- } \\
\text { 13, Challisha } \times \text { TPS-67 } \\
\text { Lal Shill } \times \text { TPS-13, Shill Bilati } \times \text { TPS-13, Lal Pakri } \times \text { Dheera, Sada Gutti } \\
\times \text { TPS-13, Sada Gutti } \times \text { Dheera, Ausha } \times \text { Dheera, Patnai } \times \text { Dheera, } \\
\text { Challisha } \times \text { TPS-13, Ausha } \\
\text { Challisha } \times \text { Dheera, Lal Shill, Shill Bilati, Lal Pakri, Sada Gutti, Patnai, } \\
\text { Challisha }\end{array}$ \\
\hline
\end{tabular}

TPS $=$ True potato seed

The maximum inter-cluster divergence (Table 2) was observed between the clusters I and V, and it was minimum between clusters II and III. The maximum intra-cluster distance was observed in cluster V and minimum in cluster I. Cluster I had only a single genotype. The crosses involving parents from most divergent clusters are expected to manifest maximum heterosis and generate wide variability in genetic architecture. Intracluster distance was being much lower than the 
intercluster one, suggested, heterogeneous and homogeneous nature between and within groups, respectively. This was further supported by an appreciable variation observed for cluster means (Table 3). ITW, TW and WL\% were the highest in cluster I; NS and TN in cluster III; PH in cluster II and DM\% in cluster V; while ITW and TW were lowest mean values in cluster V. A wide range of variation for several characters among single as well as multigenotypic cluster was observed. However, the difference was more clear for PH, NS, TW, ITW, TW, DM\% and TWL\% which has contributed largely to the total divergence. Similar results have also been reported by Desai and Jaimini (1997), Gaur el al. (1978), Sidhu and Pandita (1980) and Sidhu et al. (1981) for TW, PH, ITW and TN towards total divergence in cluster. Hence, for the improvement of different characters viz. TN, ITW, TW, DM\% and TWL\% under the present study, parents should be selected from cluster I, III and V.

Table 2. Average intra- (bold face) and intercluster distance $\left(D^{2}\right)$ of 31 potato genotypes.

\begin{tabular}{lccccc}
\hline Cluster & I & II & II & IV & V \\
\hline I & 0000 & 10.457 & 13.799 & 18.706 & 23.694 \\
II & & $\mathbf{0 . 8 1 8}$ & 3.823 & 8.798 & 14.281 \\
III & & $\mathbf{0 . 5 5 7}$ & 5.015 & 10.458 \\
IV & & & $\mathbf{0 . 7 6 2}$ & 5.169 \\
V & & & & $\mathbf{0 . 9 3 0}$ \\
\hline
\end{tabular}

Table 3. Cluster means for eight characters in 31 potato genotypes.

\begin{tabular}{lrrrrr}
\hline Characters & \multicolumn{5}{c}{ Clusters } \\
\cline { 2 - 6 } & \multicolumn{1}{c}{ I } & \multicolumn{1}{c}{ II } & III & \multicolumn{1}{c}{ IV } & V \\
\hline Days to emergence & 8.69 & 10.48 & 10.83 & 9.77 & 11.78 \\
Plant height & 42.47 & 55.00 & 51.34 & 53.29 & 51.42 \\
Number of stems/plant & 5.25 & 5.40 & 5.71 & 5.36 & 4.88 \\
Tuber numbers/plant & 9.13 & 20.66 & 20.78 & 19.69 & 13.33 \\
Individual tuber weight/plant & 41.93 & 17.48 & 14.58 & 16.43 & 8.67 \\
Tuber weight/plant & 365.00 & 290.30 & 244.28 & 186.96 & 119.13 \\
Tuber dry-matter content (\%) & 19.89 & 21.06 & 21.61 & 20.45 & 24.04 \\
Tuber weight loss due to respiration (\%) & 24.60 & 16.40 & 14.58 & 16.43 & 8.67 \\
\hline
\end{tabular}

The principal component analysis revealed that in major vector 1 the important characters responsible for genetic divergence in the major axis of differentiation were PH and TN (Table 4). In vector II which was the second axis of differentiation $\mathrm{PH}, \mathrm{TN}$ and TW were important. The role of $\mathrm{PH}$ and $\mathrm{TN}$ for both the vectors was positive across two axes which is the indication of the important components of genetic divergence in these materials.

Table 4. Latent vectors for eight characters of $\mathbf{3 1}$ potato genotypes.

\begin{tabular}{lrr}
\hline Characters & Vector I & Vector II \\
\hline Days of emergence & -0.0450 & -0.0057 \\
Plant height & -0.0064 & 0.0210 \\
Numbers of stem/plant & -0.5181 & -0.4344 \\
Tuber numbers/plant & 0.1048 & 0.1968 \\
Individual tuber weight/plant & 0.0056 & 0.0521 \\
Tuber weight/plant & -0.0823 & 0.0030 \\
Tuber dry matter content $(\%)$ & -0.6129 & -0.9156 \\
Tuber weight loss due to respiration $(\%)$ & -0.3334 & -0.4254 \\
\hline
\end{tabular}


Group consultation was also independently derived by principal component analysis to verify grouping obtained through $\mathrm{D}^{2}$ statistic in a two dimensional chart $\left(\mathrm{Z}_{1}-\mathrm{Z}_{2}\right)$. Therefore, scores obtained for the first two components were plotted against two main axis and then supper imposed with clustering (Fig. 1). This clustering pattern confirmed the results obtained by $\mathrm{D}^{2}$ analysis.

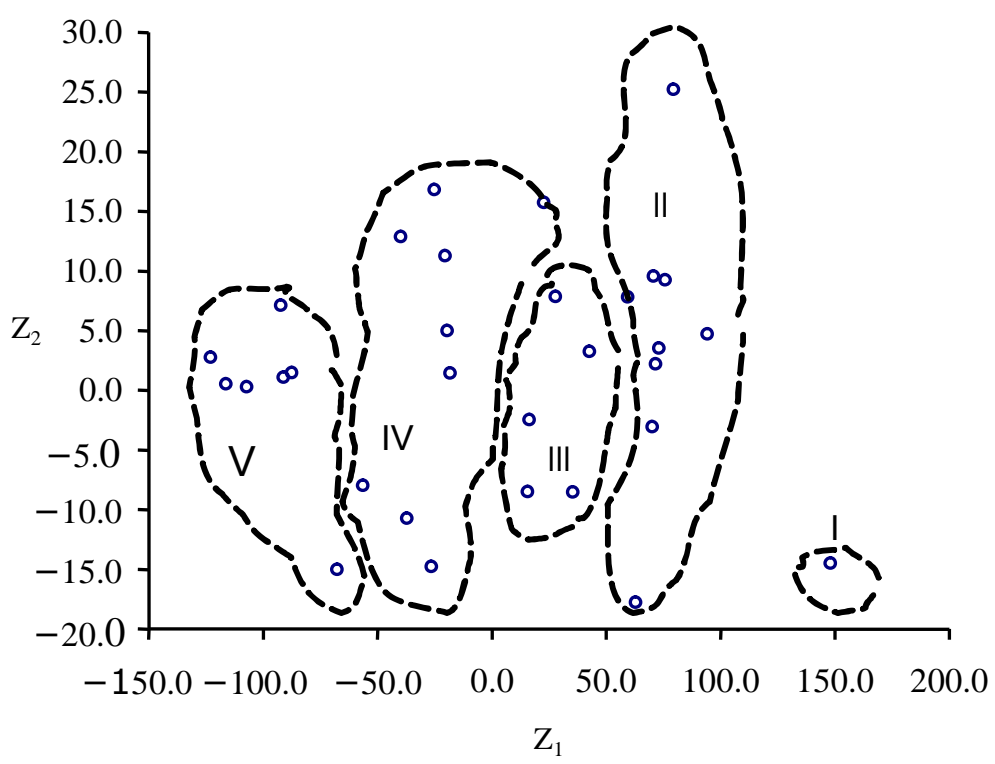

Fig.1. Scatter diagram of 31 genotypes in potato.

The crosses involving parents belonging to the maximum divergent clusters were expected to manifest maximum heterosis and also wide variability in genetic architecture. Thus crosses among the genotypes of clusters I, III and V would exhibit high heterosis and is also likely to produce new recombinants with desired characters in potato.

\section{Reference}

Desai, N.C. and S.N. Jaimini. 1997. Studies on genetic divergence in potato (Solanum tuberosum L.). Indian Potato Assoc. 24 (3\&4): 154-160.

Grag, K.C. 1988. A study of dihaploids derived from five indian cultivers of potato. Haryana J. Hort. Sci. 20: 255-260.

Gaur, P.C., P.K. Gupta and H. Kishore. 1978. Studies on genetic divergence of potato. Euphytica 27: 361368.

Mahalanobis, P.C. 1936. On the generalized distance in statistics. Proc. Nat. Sci., India 2: 49-55.

Mannan, M.A., M.S. Ahmed, M.M. Rashid, M.K.R. Bhuiyan and R. Gomes. 1993. Genetic diversity of Colocasia esculenta (L.) Schott. Indian J. Root Crops 19(2): 95-99.

Masud, M. A. T., M. A. Chowdhury, M. A. Hossain and S. M. M. Hossain. 1995. Multivariate analysis in pumpkin (Cucurbita moschata Duch ex. Poir) Bangladesh J. Pl. Breed. Genet. 8(1\&2): 45-50.

Main, M.A.K. and P.N. Bahl. 1989. Genetic divergence and hybrid performance in chickpea. Indian J. Genet. 49(1): 119-124.

Murty, B.R. and V. Arunachalam. 1966. The nature of genetic divergence in relation to breeding system in crop plant. Indian J. Genet. 26A: 188-198.

Shanmugam, A.S. and S.R.S. Rangasamy. 1982. Genetic diversity of quantitative characters in green gram (Vigna radiata L. Wilczek). Madras Agric. J. 69(10): 631-636. 
Sidhu, A.S. and M.L. Pandita. 1980. Genetic divergence for yield and its components in potato. Genetica Agraria 34: 235-244.

Sidhu, A.S., M.L. Pandita and S.K. Arora. 1981. Studies on genetic divergence in potato. J. Indian Potato Assoc. 8: 122-117.

Singh, D.P. and V.S.R K. Prasad. 1991. Genetic divergence of parents and hybrids in Solanum melongena L. Indian J. Hort. 48(2): 139-144.

Singh, S.P. and H.N. Singh. 1979. Genetic divergence in okra (Abelmoschus esculentus L. Moech) Indian J. Hort. 36(2): 166-170.

Singh, S.P., P.K. Gupta and K.P. Sharma. 1988. Genetic divergence in potato (Solanum tuberosum L.) grown in 12 environments. J. Indian Potato Assoc. 15: 45-52.

(Manuscript received on 15 January, 2007; revised on 5 August, 2007) 